\title{
AN ANALYSIS OF CONTRIBUTING FACTORS IN NURSES' ACCURACY WHILE CONDUCTING TRIAGE IN EMERGENCY ROOM
}

Ria Ramadhani Dwi Atmaja ${ }^{1 *}$, Mohammad Hidayat ${ }^{2}$, Mukhamad Fathoni

Afiliasi

1. Program Studi Farmasi Fakultas Kedokteran dan Ilmu Kesehatan UIN Maulana Malik Ibrahim Malang

2. Fakultas Kedokteran Universitas Brawijaya

3. Program Studi Magister Keperawatan Fakultas Kedokteran Universitas Brawijaya

Dikirim 24 Juni 2020

Direvisi 13 November 2020

Diterima 19 November 2020

Dipublikasikan 30 November 2020

*Corresponding author

Email :

ria.ramadhani85@yahoo.com

\begin{abstract}
ABSTRAK
Triage bertujuan untuk memberikan prioritas perawatan kepada pasien sesuai tingkat keurgensiannya. Perawat IGD dalam melakukan triage harus berdasarkan suatu standar prosedur. Untuk dapat melakukan prosedur triage yang tepat, perawat harus memiliki kompetensi yang dibutuhkan dalam triage yang terdiri dari pengetahuan, skill/ketrampilan dan sikap. Selain kompetensi, ada beberapa faktor lain yangberperan, yaitu faktor intrinsik perawat. Tujuan penelitian ini adalah menganalisa faktor apa saja yang berhubungan dengan ketepatan perawat dalam melakukan prosedur triage di instalasi gawat darurat. Rancangan penelitian ini menggunakan analitik korelasional dengan pendekatan cross sectional. Populasi pada penelitian ini adalahkeseluruhan perawat yang bekerja aktif di Instalasi Gawat DaruratRSUD di Kabupaten Malang dan Kota Blitardan jumlah sampel 32 responden dengan menggunakan teknik total populasi.Instrumen yang digunakan adalah lembar observasi dan kuesioner. Data penelitian dianalisis menggunakan analisis multivariat Partial Least Squares (PLS). Hasil analisis multivariat menunjukkan terdapat hubungan tingkat pengetahuan ( $p$-value 0.000), tingkat keterampilan ( $p$-value 0.000), sikap ( $p$-value 0.000$)$, faktor intrinsik ( $p$-value 0.000) terhadap ketepatan perawat dalam melakukan prosedur triage. Berdasarkan hasil tersebut, perlunya peran pihak manajemen rumah sakit dapat meningkatkan kompetensi perawat dalam melakukan triage, terutama dengan mengikutsertakan dalam pelatihan kegawatdaruratan lanjut dan pelatihan triage.
\end{abstract}

Kata kunci :Analisis Faktor, Ketepatan Prosedur, Triage, Perawat

\begin{abstract}
Triage is aimed to arrange treatment priority to patients with different levels of urgency. These nurses who are responsible for triage must conduct standardized procedure. Hence, these nurse must acquire certain competency required to conduct triage. The competency includes basic knowledge, skills and attitude. Besides that, there are several contributing factors playing significant role in triage procedure implementation, which is intrinsic factors. Regarding to those factors, this study aimed to analyze those contributing factors affecting nurses' accuracy in doing triage procedure in emergency room. This study employed correlational analytic design accompanied with cross sectional approach. The population in this study was all nurses who worked actively in the Emergency Room at RSUD in Malang Regency and Blitar City and thirty two respondents are taken as the samples using population total method. The data is collected using observation sheet and questionnaire. The data analyzed through Partial Least Squares (PLS). It is showed that knowledge level ( $p$-value 0.000), skill level ( $p$-value 0.000), attitude ( $p$-value 0.000), intrinsic factors ( $p$-value 0.000) are related to nurses' accuracy in implementing triage procedure. Therefore, based on those findings, the hospital's management is suggested to improve their nurses' competency in implementing triage, especially by recommending them to participate in advanced emergency training and triage course.
\end{abstract}

Keywords: Factor Analysis, Procedure Accuracy, Triage, Nurse

Sitasi jurnal :

Atmaja RRD, Hidayat M,,Fathoni M. 2020. An Analysis Of Contributing Factors In Nurses' Accuracy While Conducting Triage In Emergency Room. Jurnal Ilmu Keperawatan 8 (2): 135-145. Doi: 10.21776/ub.jik.2020.008.02.11 


\section{PENDAHULUAN}

Proses triage berkembang sebagai suatu cara yang efektif untuk memisahkan pasien yang membutuhkan perhatian medis segera dari pasien yang masih bisa menunggu untuk mendapatkan perawatan yang simultan (Mirhaghi \& Roudbari, 2011). Menurut Ajani (2012) triage di Instalasi Gawat Darurat (IGD) adalah proses dimana perawat melakukan penilaian terhadap seorang pasien pada saat kedatangannya di ruang gawat darurat untuk menentukan urgensi dan jenis masalah dan menunjuk sumber daya kesehatan yang sesuai. Sistem triage yang efektif akan meningkatkan pemberian kualitas perawatan kepada pasien, memperpendek lama perawatan pasien, dan menurunkan waktu tunggu pasien (Grossman, 2003, National Emergency Nurses Affiliation, 2009).

Skala triagememungkinkan perawat untukmembuat keputusan triage yang sistematis dan akurat. Keputusan triageyangakuratolehseorangperawatakan menentukan seberapa cepat pasien menerima perawatan medis di IGD sesuai dengan tingkat keakutan kondisi pasien (Samons, 2012). Perawat IGD dalam melakukan triage harus berdasarkan suatu standar prosedur (Ignatavicius, 2006 dalam Krisanty, 2009). Berdasarkan hasil penelitian yang dilakukan oleh Gurning., dkk. (2011) menyebutkan bahwa sebagian besar petugas kesehatan IGD yaitu sebanyak 18 responden $(56,3 \%)$ dapat melaksanakan tindakan triage berdasarkan prioritassesuai prosedur. Hasil penelitian yang lain dilakukan oleh Sunaryo (2010) tentang beberapa hasil pelaksanaan triage oleh perawat di gawat darurat Rumah Sakit Immanuel Bandung antara lain memperlihatkan kegiatan survei primer sesuai dengan standar prosedur dengan kriteria baik sebesar $0 \%$. Prinsip seleksi sesuai prosedur dengan kriteria baik sebesar 0\%. Penilaian prioritas sesuai prosedur dengan kriteria baik sebesar 96\%. Kegiatan tindakan triage sesuai prosedur dengan kriteria cukup sebesar 66\%.

Untuk dapat melakukan prosedur triage yang tepat, perawat gawat darurat harus memiliki kompetensi yang dibutuhkan dalam triage yang terdiri dari pengetahuan dasar tentang triage, skill/ ketrampilan dan sikap yang dibutuhkan untuk melakukan triage yang akurat (ENA, 2011). Beberapa faktor telah diidentifikasi dapat mempengaruhi kesesuaian penilaian perawat dalam melakukan triage diantaranya yang dilakukan oleh Chen, et al (2010) menyebutkan bahwa pengalaman perawat bekerja di IGD, tingkat pendidikan perawat, umur, tingkat rumah sakit dan model pemberian triage dapat mempengaruhi perawat dalam melakukan tindakan triage. Penelitianyang lainnya juga menyebutkan untuk melakukan triage dengan benar membutuhkan proses kognitif yang tinggi dan juga keterampilan, keahlian, kompetensi, kualifikasi dan kesiapan dalam pengambilan keputusan triage.

Beberapa peneliti membedakan faktor yang berperan dalam melakukan triage di IGD menjadi faktor individual dan faktor kontekstual. Faktor individual merujuk pada faktor internal/intrinsik diantaranya rasa takut membuat kesalahan dalam situasi berbahaya, wawasan, kualifikasi klinis dan kemampuan perawat sedangkan faktor kontekstual merujuk pada faktor eksternal/ekstrinsik seperti: stres lingkungan kerja, beban kerja yang tinggi dan kepadatan lingkungan kerja (Gerdtz, 2003; Fry, 2004; Andersson., Omberg., Svedlund, 2006; Göransson, 2006).Proses triage yang dilakukan tidak sesuai prosedur dapat mempengaruhi keputusan perawat dalam menentukan kategori pasien. Hal ini berdampak pada waktu tunggu pasien sampai mendapatkan intervensi medis akan berkepanjangan dan pasien berpotensi untuk kondisi yang semakin memburuk, serta tambahan biaya pengobatan bagi pasien.

Berdasarkan studi pendahuluan, kondisi IGD di Rumah sakit I dan Rumah sakit II memiliki karakteristik yang hampir sama, di mana jumlah kunjungan pasien rata-rata setiap harinya sekitar 40-45 pasien dan jumlah kunjungan pasien per minggu adalah 300350 pasien. Sebagai rumah sakit pemerintah Kelas B Non Pendidikan, RS I dan RS II merupakan rumah sakit rujukan utama di wilayahnya dan menerima pasien dari pelayanan kesehatan lain seperti balai pengobatan, puskesmas serta rumah sakit lain di sekitarnya. Proses triage di kedua IGD dilakukan oleh perawat. Karakteristik perawat dari segi pengalaman bekerja di IGD sangat beragam dengan pengalaman paling rendah yaitu selama 1 tahun dan pengalaman paling tinggi yaitu selama 16 tahun. Pelatihan yang didapatkan di IGD, hampir semua perawat di dua rumah sakit tersebut telah mengikuti BLS dan PPGD dan belum pernah ada satupun yang mendapatkan pelatihan tentang triage. Untuk pelaksanaan triage di IGD, berdasarkan hasil observasi, peneliti menemukan bahwa terdapat sebagian perawat tidak melakukan 
triage pada saat menerima pasien baru. Perawat IGD langsung menempatkan pasien berdasarkan hasil triage yang mereka lakukan di depan pintu IGD secara visual triage dan tidak melakukan pemeriksaan terlebih dahulu di tempat tidur triage, dan tentu saja hal tersebut bisa mempengaruhi tingkat keakuratan perawat dalam menentukan kategori pasien.

Tujuan dari penelitian ini adalah menganalisa faktor-faktor yang berhubungan dengan ketepatan perawat dalam melakukan prosedur triage, yang meliputi: tingkat pengetahuan, tingkat keterampilan, sikap perawat, dan faktor intrinsik perawat.Dengan diketahuinya faktor-faktor yang berhubungan dengan pelaksanaan triage, diharapkan dapat menjadi masukan dalam pemberian asuhan keperawatan dan pelaksanaan triage dengan memperhatikan faktor-faktor yang berhubungan sehingga dapat melaksanakan triage dengan tepat dan pasien mendapatkan pelayanan sesuai dengan kondisi dan permasalahan yang dialami.

\section{METODE}

Rancangan penelitian yang digunakan adalah analitik korelasional dengan pendekatan cross sectional. Desain ini digunakan untukmelihat hubungan antara pengetahuan perawat tentang triage, keterampilan perawat dalam triage, sikap perawat yang mendukung dalam melakukan triage dan faktorfaktor intrinsik terhadap ketepatan perawat dalam melakukan prosedur triage. Faktor intrinsik perawat yang diteliti meliputi umur, tingkat pendidikan, pengalaman kerja dan pengalaman pelatihan.

Populasi pada penelitian ini adalahkeseluruhan perawat yang bekerja aktif di Instalasi Gawat Darurat RSUD di Kabupaten Malang dan Kota Blitar. Jumlah sampel dalam penelitian ini adalah 32 responden dengan menggunakan teknik total populasi.

Instrumen yang digunakan adalah lembar observasi dan kuesioner. Variabel pengetahuan diukur dengan menggunakan kuesioner yang telah dibuat oleh peneliti terdiri dari 10 pertanyaan yang meliputi konsep dasar triage, prinsip triage, peran perawat triage, konsep pemeriksaan fisik dan initial assessment.Uji validitas instrumen pengetahuan perawat mengenai pelaksanaan triage menunjukkan bahwa instrument kuesioner valid dengan nilai $r_{\text {hitung }}$
$=0.557-0.964$, yang $>$ dari $r_{\text {tabel }}\left(r_{\text {tabel }}=0.300\right)$ pada semua pertanyaan. Kuesioner juga reliable dengan nilai cronbach alfa $=0.917$.Variabel keterampilan diukur dengan menggunakan lembar observasi yang berisi mengenai keterampilan perawat yang dibutuhkan dalam melakukan triage menurut Emergency Nurses Association (2011)dan American Nurses Association (2011) (Harding et al, 2013). Variabel sikap perawat yang mendukung pelaksanaan triage diukur dengan menggunakan kuesioner berdasarkan Caring NursePatient Interactions Scale: 23-item Version (CNPI23) dengan menggunakan skala likert (Cossette et al, 2005). Variabel pengetahuan, keterampilan dan sikap perawat dalam pelaksanaan triage termasuk ke dalam variabel kompetensi perawat. Variabel ketepatan perawat diukur dengan menggunakan variabel ketepatan perawat dalam melakukan prosedur triage diukur dengan menggunakan lembar observasi untuk mengukur kesesuaian responden dalam menilai,memilah dan memprioritaskan pasien sesuai kegawatannya berdasarkan prosedur yang merujuk pada indikator praktek klinis (ruang triage) (Depkes RI, 2009). Variabel data penelitian kemudian dianalisis dengan menggunakan analisis multivariat Partial Least Squares (PLS).

\section{HASIL}

Tabel 1:Karakteristik Responden berdasarkan Umur

\begin{tabular}{ccc}
\hline $\begin{array}{c}\text { Umur } \\
\text { (Tahun) }\end{array}$ & $\begin{array}{c}\text { Frekuensi } \\
\text { (n) }\end{array}$ & $\begin{array}{c}\text { Prosentase } \\
(\%)\end{array}$ \\
\hline$<25$ & 1 & 3,1 \\
$26-30$ & 6 & 18,8 \\
$31-35$ & 10 & 31,3 \\
$36-40$ & 11 & 34,3 \\
$>40$ & 4 & 12,5 \\
Total & 32 & 100 \\
\hline
\end{tabular}

Sumber : Data Primer (2016)

Berdasarkan tabel1 menunjukkan karakteristik responden yang bekerja di IGD sebagian besar memiliki usia 36-40 tahun yaitu 11 responden $(34,4 \%)$ dan 31 35 tahun yaitu 10 responden $(31,3 \%)$, hasil tersebut menunjukkan bahwa sebagian besar usia responden termasuk usia dewasa yang merupakan usia produktif dalam bekerja. 
Tabel 2:Karakteristik Responden Berdasarkan TingkatPendidikan Perawat di Instalasi Gawat Darurat

\begin{tabular}{ccc}
\hline $\begin{array}{c}\text { Tingkat } \\
\text { Pendidikan }\end{array}$ & $\begin{array}{c}\text { Frekuensi } \\
\text { (n) }\end{array}$ & $\begin{array}{c}\text { Prosentase } \\
(\%)\end{array}$ \\
\hline SPK & 0 & 0 \\
D3 & 26 & 81,3 \\
S1 & 6 & 18.7 \\
S2 & 0 & 0 \\
Total & 32 & 100 \\
\hline
\end{tabular}

Sumber : Data Primer (2016)

Berdasarkan tabel2 menunjukkan karakteristik responden yang bekerja di IGD sebagian besar memiliki tingkat pendidikan D3 Keperawatan berjumlah 26 responden (81,3\%) sedangkan S1 Keperawatan sebanyak 6 responden $(18,7 \%)$, artinya bahwa karakteristik responden berdasarkan tingkat pendidikan masih termasuk dalam kategori menengah.

Tabel 3:Karakteristik Responden Berdasarkan Berdasarkan Pengalaman Kerja

\begin{tabular}{ccc}
\hline $\begin{array}{c}\text { Pengalaman } \\
\text { Kerja (Tahun) }\end{array}$ & $\begin{array}{c}\text { Frekuensi } \\
(\mathrm{n})\end{array}$ & $\begin{array}{c}\text { Prosentase } \\
(\%)\end{array}$ \\
\hline$<1$ & 0 & 0 \\
$1-3$ & 5 & 15,6 \\
$4-6$ & 5 & 15,6 \\
$7-9$ & 7 & 21,9 \\
$>10$ & 15 & 46,9 \\
Total & 32 & 100 \\
\hline
\end{tabular}

Sumber : Data Primer (2016)

Berdasarkan tabel 3 menunjukkan karakteristik responden berdasarkan pengalaman kerja di IGD sebagian besar $>10$ tahun yaitu sebanyak 15 responden (46\%) sedangkan pengalaman kerja 7-9 tahun sebesar 7 responden (22\%), pengalaman selama 4-6 tahun sebesar 5 responden(16\%) dan 1-3 tahun sebanyak 5 responden (16\%), hal ini menunjukkan bahwa sebagian besar perawat mempunyai pengalaman yang cukup lama bekerja di IGD.
Tabel 4: Karakteristik Responden Berdasarkan Pelatihan yang pernah diikuti di Instalasi Gawat Darurat

\begin{tabular}{ccc}
\hline $\begin{array}{c}\text { Pengalaman } \\
\text { Pelatihan }\end{array}$ & $\begin{array}{c}\text { Frekuensi } \\
(\mathrm{n})\end{array}$ & $\begin{array}{c}\text { Prosentase } \\
(\%)\end{array}$ \\
\hline BLS & 28 & 37,3 \\
ALS & 1 & 1,4 \\
TRIAGE & 0 & 0 \\
BTLS & 10 & 13,3 \\
ACLS & 1 & 1,4 \\
MANAG.BENCANA & 4 & 5,3 \\
GELS & 1 & 1,4 \\
PPGD & 25 & 33,3 \\
LAINNYA & 5 & 6,6 \\
Total & 75 & 100 \\
\hline
\end{tabular}

Sumber : Data Primer (2016)

Berdasarkan tabel4 menunjukkan karakteristik responden berdasarkan pelatihan yang pernah diikuti di IGD ada beberapa perawat yang mempunyai pengalaman pelatihan lebih dari satu, sehingga didapatkan hasil bahwa 28'responden (87,5\%) pernah mengikuti BLS, sedangkan yang mengikuti PPGDsebanyak 25 responden (78\%) responden, pelatihan BTLS sebesar 10 responden (31\%), sedangkan yang mengikuti pelatihan lanjutan seperti ACLS dan ALS ada 1 responden (3\%), yang mengikuti GELS sebanyak 1 responden(3\%), sedangkan yang mengikuti managemen bencana sebanyak 4 responden $(12,5 \%)$, berdasarkan hasil tersebut menunjukkan bahwa perawat yang bekerja di IGD persyaratan utama adalah telah mengikuti BLS dan PPGD.

Tabel 5: Distribusi Frekuensi Responden berdasarkan Tingkat Pengetahuan tentang Triage

\begin{tabular}{ccc}
\hline $\begin{array}{c}\text { Variabel } \\
\text { Tingkat }\end{array}$ & $\begin{array}{c}\text { Frekuensi } \\
\text { (n) }\end{array}$ & $\begin{array}{c}\text { Prosentase } \\
(\%)\end{array}$ \\
\hline Pengetahuan & & 0 \\
Kurang baik & 0 & 47 \\
Cukup Baik & 15 & 53 \\
Baik & 17 & 100 \\
Total & 32 & \\
\hline
\end{tabular}

Sumber : Data Primer (2016)

Berdasarkan tabel 5 menunjukkan responden yang memiliki tingkat pengetahuan cukup baik sebanyak 15 reponden (47\%) sedangkan tingkat pengetahuan baik sebanyak 17 responden (53\%), hal ini menunjukkan bahwa sebagian besar responden 
yang bekerja di IGD memiliki tingkat pengetahuan yang baik tentang triage.

Tabel 6: Distribusi Frekuensi Responden berdasarkan Tingkat Keterampilan

\begin{tabular}{ccc}
\hline $\begin{array}{c}\text { Variabel } \\
\text { Tingkat }\end{array}$ & $\begin{array}{c}\text { Frekuensi } \\
(\mathrm{n})\end{array}$ & $\begin{array}{c}\text { Prosentase } \\
(\%)\end{array}$ \\
Keterampilan & & \\
\hline Kurang baik & 0 & 0 \\
Cukup Baik & 4 & 12,5 \\
Baik & 28 & 87,5 \\
Total & 32 & 100 \\
\hline
\end{tabular}

Sumber : Data Primer (2016)

Berdasarkan tabel 6 menunjukkan responden dengan keterampilan cukup baik sebanyak 4 reponden $(12,5 \%)$ sedangkan responden dengan keterampilan baik sebanyak 28 responden $(87,5 \%)$, artinya bahwa sebagian besar respondentelah memiliki ketrampilan yang sudah baik dalam melakukan triage.

Tabel 7: Distribusi Frekuensi Responden berdasarkan Sikap yang mendukung dalam Melakukan Triage

\begin{tabular}{ccc}
\hline $\begin{array}{c}\text { Variabel } \\
\text { Sikap Responden }\end{array}$ & $\begin{array}{c}\text { Frekuensi } \\
\text { (n) }\end{array}$ & $\begin{array}{c}\text { Prosentase } \\
(\%)\end{array}$ \\
\hline Negatif & 13 & 41 \\
Positif & 19 & 59 \\
Total & 32 & 100 \\
\hline
\end{tabular}

Sumber : Data Primer (2016)

Berdasarkan tabel 7 menunjukkan sikap responden negatif sebanyak 13 responden (41\%), sedangkan sikap responden positif sebanyak 19 reponden (59\%) artinya sebagian besar sikap responden yang mendukung dalam melakukan triage di IGD adalah positif.

Tabel 8: Prosentase Rata-Rata Ketepatan Perawat dalam Melakukan Prosedur Triage

\begin{tabular}{ccc}
\hline Variabel & RS I & RS II \\
$\begin{array}{c}\text { Ketepatan Perawat } \\
\text { terhadap Prosedur } \\
\text { Triage }\end{array}$ & $(\%)$ & $(\%)$ \\
\hline Total nilai & 82 & 81 \\
\hline
\end{tabular}

Sumber : Data Primer (2016)

Berdasarkan tabel8. menunjukkan rata-rata prosentase ketepatan perawat dalam melakukan prosedur triage di kedua rumah sakit menunjukkan hasil yang hampir sama yaitu $82 \%$ di RS I dan $81 \%$ di RS II, hal ini menunjukkan bahwa ketepatan perawat dalam melakukan prosedur triage di IGD kedua rumah sakit tersebut sudah baik.

Tabel 9:Pengujian Outer Model Struktural

\begin{tabular}{llc}
\hline $\begin{array}{r}\text { Variabel } \\
\text { Penelitian }\end{array}$ & Indikator & P-value \\
\hline & JK & 0.374 \\
Faktor & Umur & 0.000 \\
Intrinsik & Pendidikan & 0.000 \\
(X1) & Pengalaman & 0.000 \\
& Pelatihan & 0.000 \\
\hline Kompetensi & Pengetahuan & 0.000 \\
Perawat & Keterampilan & 0.000 \\
(Y1) & Sikap & 0.000 \\
\end{tabular}

Sumber : Data Primer (2016)

Berdasarkan pada tabel 9 pengujian outer model struktural variabel Faktor Intrinsik (X1), dapat dijelaskan bahwa indikator yang memiliki $p$-value kurang dari 0,05 meliputi umur, pendidikan, pengalaman, dan pelatihan. Hal ini menunjukkan bahwa konstruk variabel Faktor Intrinsik (X1) signifikan. Pada variabel Kompetensi Perawat (Y1) di atas, dapat dijelaskan bahwa semua item penyusun variabel Kompetensi Perawat (Y1) memiliki memiliki $p$-value kurang dari 0.05. Sehingga, dapat dikatakan bahwa semua indikator signifikan.

Tabel 10:Hasil Pengujian Efek Mediasi Variabel Kompetensi Perawat

\begin{tabular}{lllc}
\hline $\begin{array}{c}\text { Variabel } \\
\text { Independen }\end{array}$ & $\begin{array}{l}\text { Variabel } \\
\text { Mediasi }\end{array}$ & $\begin{array}{l}\text { Variabel } \\
\text { Dependen }\end{array}$ & $\begin{array}{c}\text { Koefisien } \\
\text { Jalur }\end{array}$ \\
\hline $\begin{array}{l}\text { Faktor } \\
\text { Intrinsik }\end{array}$ & $\begin{array}{l}\text { Kompetensi } \\
\text { Perawat }\end{array}$ & $\begin{array}{l}\text { Ketepatan } \\
\text { Prosedur } \\
\text { Triage }\end{array}$ & 0.521 \\
\hline
\end{tabular}

Sumber : Data Primer (2016)

Berdasarkan pada tabel10 di atas, didapatkan pengaruh tak langsung variabel Faktor Intrinsik (X1) terhadap Ketepatan Prosedur Triage (Y2) dengan melalui variabel Kompetensi Perawat (Y1) sebagai mediasi adalah sebesar 0.521 dan $p$-value sebesar 0.000. $P$-value kurang dari 0.05 mengindikasikan bahwa pengaruh tak langsung terbentuk secara signifikan. Sehingga, terbukti bahwa variabel Kompetensi Perawat (Y1) merupakan variabel mediasi yang menghubungkan pengaruh variabel Faktor Intrinsik (X1) terhadap Ketepatan Prosedur Triage (Y2). 


\section{PEMBAHASAN}

\section{Hubungan Tingkat Pengetahuan Perawat tentang triage terhadap Ketepatan Perawat dalam Melakukan Prosedur Triage}

Berdasarkan tabel 1menunjukkan bahwa sebagian besar responden yang bekerja di IGD memiliki tingkat pengetahuan yang baik tentang Triage (53\%). Hasil tersebut kemungkinan disebabkan karena sebagian besar responden memiliki pengalaman kerja lebih dari 7 tahun dan telah mengikuti lebih dari 2 pelatihan kegawatdaruratan. Hal tersebut sejalan dengan penelitian oleh Rahmawati., dkk (2013) yang menyebutkan bahwa tingkat pengetahuan dan praktek dalam triage menunjukkan hasil yang lebih baik dari sebelum dilakukannya pelatihan. Pengetahuan responden pada saat pra-pelatihan adalah moderat tapi meningkat menjadi baik setelah pelatihan dan tidak satupun dari responden yang menunjukkan tingkat pengetahuan yang rendah. Hal tersebut menunjukkan bahwa dengan pemberian pelatihan dapat meningkatkan pengetahuan perawat terkait triage. Akan tetapi mengingat bahwa dampak pelatihan akan berkurang dari waktu ke waktu maka dibutuhkan adanya pelatihan secara berkelanjutan.

Pengetahuan juga sangat erat kaitannya dengan pendidikan dimana diharapkan seseorang dengan pendidikan tinggi, maka orang tersebut akan makin luas pengetahuannya. Hal ini sesuai dengan hasil penelitan yang menunjukkan bahwa responden dengan latar pendidikan S1 keperawatan memiliki tingkat pengetahuan yang baik. Akan tetapi seseorang yang berpendidikan lebih rendah tidak berarti berpengetahuan rendah pula. Menurut Notoatmodjo (2007) seseorang dengan pendidikan rendah juga bisa mempunyai pengetahuan yang baik dikarenakan banyaknya faktor yang mempengaruhi antara lain pengalaman dan usia. Sehingga semakin bertambah usia akan semakin bertambah pula daya tangkap dan pola pikirnya, sehingga pengetahuan yang diperoleh semakin membaik.

Dari hasil uji statistik didapatkan hubungan yang signifikan dan positif antara tingkat pengetahuan dengan ketepatan perawat dalam melakukan prosedur triage ( $p$-value $=0,000, \mathrm{t}$ statistic $=5.263)$. Hasil tersebut menunjukkan bahwa semakin tinggi tingkat pengetahuan maka ketepatan perawat dalam melakukan prosedur juga semakin baik. Hal ini sejalan dengan penelitian oleh Lusiana (2011) tentang pelaksanaan triage di IGD Rumah Sakit Puri Indah Jakarta bahwasanya pengetahuan sangat mempengaruhi dalam pelaksanaan triage. Pengetahuan tentang triage yang dimiliki oleh petugas kesehatan IGD akan sangat membantu petugas dalam mengenal kasus-kasus kegawatdaruratan juga berguna untuk kualitas pelayanan dan dapat mencegah kematian serta kecacatan lebih lanjut. Sunaryo, (2004) mengatakan bahwa pengetahuan merupakan hal yang sangat mempengaruhi petugas kesehatan dalam menerapkan dan menggunakan materi sesuai dengan situasi dan kondisi yang nyata.

\section{Hubungan Tingkat Keterampilan Perawat terhadap Ketepatan Perawat dalam Melakukan Prosedur Triage}

Berdasarkan hasil penelitian pada tabel 2 tentang tingkat keterampilan perawat dalam triage didapatkan sebagian besar responden memiliki tingkat keterampilan yang baik $(87,5 \%)$, sedangkan 4 responden $(12,5 \%)$ memiliki tingkat keterampilan yang cukup. Hasil uji statistik didapatkan p-value < $0.05(t$ statistic $=11.357)$ maka Ho ditolak sehingga terdapat hubungan antara keterampilan perawat dalam triage terhadap ketepatan perawat dalam melakukan prosedur triage. Arah korelasi yang positif menunjukkan bahwa semakin tinggi tingkat keterampilan perawat maka ketepatan perawat dalam melakukan prosedur triage juga semakin tinggi.

Notoatmodjo (1996) dalam Yuliastuti (2007) mengutarakan bahwa semakin tinggi keterampilan yang dimiliki oleh tenaga kerja, semakin efisien badan, tenaga dan pemikirannya dalam melaksanakan pekerjaan. Sirait (2006) dalam penelitiannya juga menyatakan bahwa pendidikan dan latihan akan memberikan pegawai keterampilan yang mereka butuhkan dan dengan adanya keterampilan tersebut dapatmengurangirasatakutmerekadalammenghadapi tugas-tugas baru. Penelitian yang dilakukan oleh Pitoyo (2000), yang menghasilkan bahwa terdapat hubungan antara kemampuan (pengetahuan dan keterampilan) dengan kinerja perawat.

Beberapa faktor telah diidentifikasi memiliki kontribusi terhadap keterampilan perawat dalam triage. Diantaranya yang telah dilakukan oleh Chung 
(2005) menyebutkan bahwa pengalaman pelatihan dapat meningkatkan keterampilan perawat tentang triage untuk mengidentifikasi skala prioritas pasien, mendiagnosis pasien, dan memberikan intervensi keperawatan di IGD. Hubungan antara pengalaman kerja dan pencapaian keterampilan telah dijelaskan oleh Benner, dijelaskan bahwa seorang perawat mengembangkan proses keterampilan dan pendidikannya melalui pengalaman klinis dan setelah melalui hal tersebut kemampuan pengambilan keputusan mereka akan berubah dan benar.

Penelitian yang dilakukan oleh Fathoni., et al. (2013) tentang hubungan antara pengetahuan tentang triage, pelatihan, pengalaman kerja terhadap keterampilan triage pada perawat di beberapa rumah sakit di Jawa Timur menunjukkan hasil bahwa tingkat keterampilan perawat berada dalam level moderat. Hasil tersebut kemungkinan disebabkan karena perawat IGD memiliki lebih banyak pengalaman, dan 82,3\% dari mereka telah bekerja di bagian triage. Selain itu, disebutkan juga bahwa mayoritas perawat IGD berkolaborasi dengan dokter dalam melakukan proses triage, sehingga adanya kolaborasi tersebut dapat membantu perawat untuk memiliki keterampilan triage dalam pengambilan keputusan yang tepat pada beberapa keadaan. Penelitian tersesebut juga menghasilkan bahwa pengalaman pelatihan dan pengetahuan memiliki hubungan positif dengan keterampilan triage yang mencerminkan bahwa semakin tinggi pengetahuan dan pelatihan yang diikuti perawat, maka keterampilan tentang triage juga akan berkembang.

Pada hasil penelitian terdapat 4 responden $(12,5 \%)$ yang memiliki tingkat keterampilan cukup. Hasil prosentase ketepatan dalam melakukan prosedur triage yang didapatkan dari 4 responden tersebut juga di bawah rata-rata. Hal ini kemungkinan disebabkan oleh kurangnya pengalaman pelatihan dan pengetahuan yang dimiliki mengenai triage. Oleh karena itulah, perlunya pihak manajemen rumah sakit memberikan kesempatan kepada para perawat untuk mengikuti beberapa pelatihan kegawatdaruratan, terutama pselatihan yang berkaitan dengan triage dan kegawatdaruratan lanjut, mengingat masih belum banyak perawat di kedua rumah sakit tersebut yang mengikuti pelatihan kegawat-daruratan lanjut (ALS, ATLS) dan belum ada satupun perawat yang mengikuti pelatihan triage. Selain itu, diharapkan juga memberi kesempatan kepada perawat untuk mendapatan pendidikan berkelanjutan sehingga dengan adanya pendidikan lanjut dan pemberian pelatihan kegawatdaruratan akan dapat meningkatkan pengetahuan dan keterampilan perawat sehingga ketepatan pelaksanaan prosedur triage akan lebih meningkat dan outcome yang didapatkan oleh pasien semakin meningkat pula.

\section{Hubungan Sikap Perawat terhadap Ketepatan Perawat dalam Melakukan Prosedur Triage}

Berdasarkan hasil penelitian tentang sikap responden yang mendukung dalam melakukan prosedur triage didapatkan sebagian besar responden memiliki sikap yang positif yaitu sebanyak 19 responden (59\%). Dari sejumlah 19 orang responden yang memiliki sikap positif yang melakukan tindakan triage yang sesuai prosedur dan di atas rata-rata sebanyak 14 orang responden $(73,7 \%)$. Hasil uji statistik didapatkan $p$-value $\alpha(0.000<0.05)$ maka Ho ditolak sehingga terdapat hubungan antara sikap perawat terhadap ketepatan perawat dalam melakukan triage prosedur.

Notoatmodjo (2007), mengemukakan bahwa tindakan yang dilakukan individu cenderung dipengaruhi oleh informasi dan pengetahuan yang dimilikinya. Sikapyang positif terhadap suatu informasi yang diterima seseorang dapat mempengaruhi setiap tindakan yang akan dilakukannya. Seseorang yang bersikap positif akan cenderung untuk memahami dengan benar setiap informasi atau pengetahuan yang ada, sebaliknya sikap yang negatif terkadang akan memberikan pemahaman informasi yang salah.

Hasil penelitian lain yang dilakukan oleh Lusiana (2011) tentang pelaksanaan triage di IGD Rumah Sakit Puri Indah Jakarta menunjukkan bahwasanya sikap sangat mempengaruhi dalam pelaksanaan triage. Sikap itu dapat terbentuk dari beberapa faktor yang mempengaruhi, salah satunya orang lain yang dianggap penting atau orang yang dihormati atau disegani (Gurning., dkk, 2013). Hal yang mendukung sikap positif responden terhadap ketepatan dalam melakukan prosedur triage berdasarkan analisa peneliti yaitu adanya supervisi yang dilakukan oleh koordinator/kepala shift jaga dan kepala ruang IGD yang selalu memantau kerja bawahannya. Bahkan di 
RS I setiap pagi selalu diadakan pertemuan diantara seluruh tenaga kesehatan yang bekerja di IGD tersebut untuk membahas permasalahan-permasalahan yang dihadapi ketika memberikan pelayanan kesehatan, dan hal tersebut kemungkinan bisa membentuk sikap yang positif diantara para perawat.

\section{Hubungan Faktor Intrinsik terhadap Ketepatan Perawat dalam Melakukan Prosedur Triage}

Berdasarkan hasil uji statistik dengan menggunakan Partial Least Squares (PLS) pada tabel 6 didapatkan pengaruh tak langsung variabel faktor intrinsik terhadap ketepatan perawat dalam melakukan prosedur triage melalui variabel kompetensi perawat sebagai mediasi dengan koefisien jalur sebesar 0.521 dan $p$-value sebesar 0.000 ( $p$-value< 0.05). Hasil tersebut mengindikasikan bahwa faktor intrinsik memiliki hubungan yang signifikan dengan ketepatan perawat dalam melakukan prosedur triage melalui variabel kompetensi perawat tentang triage. Selain itu, berdasarkan pada tabel pengujian outer model struktural variabel faktor intrinsik (Tabel 5), disebutkan bahwa semua indikator yang menyusun faktor intrinsik meliputi umur, tingkat pendidikan, pengalaman kerja, dan pelatihan memiliki p-value kurang dari 0,05. Hal ini menunjukkan bahwa keempat indikator tersebut signifikan dalam membentuk faktor intrinsik seorang perawat dan mendukung dalam meningkatkan ketepatan perawat dalam melakukan prosedur triage.

Dari hasil penelitian menunjukkan bahwa perawat dengan umur di atas 36 tahun memiliki skor keakuratan yang baik (>80\%). Hal ini sesuai dengan hasil penelitian oleh Sammons (2012) yang menyebutkan bahwa karakteristik umur perawat menjadi prediktor yang signifikan terhadap keakuratan perawat ketika melakukan triage pada pasien dengan gejala infark miokard akut (IMA). Menurut Sammons (2012) semakin tinggi umur seorang perawat, semakin besar kemungkinan keakuratan perawat ketika melakukan triage. Perawat yang sudah berumur mungkin memiliki kemampuan pengkajian, keterampilan, berpikir kritis yang lebih baik, dan telah mampu melakukan sintesis terhadap riwayat kesehatan dan gejala klinis yang ditunjukkan oleh pasien. Hal tersebut juga didukung oleh korelasi yang tinggi antara umur dan pengalaman.
Penelitian yang lain juga dilakukan oleh Ikhsan (2014) yang meneliti tentang pemahaman perawat dalam penerapan triage. Pada hasil penelitian disebutkan perawat yang tergolong usia madya memiliki pemahaman yang baik tentang penerapan triage. Pada usia madya, individu akan lebih berperan aktif dalam masyarakat dan kehidupan sosial. Kemampuan intelektual, pemecahan masalah, dan kemampuan verbal dilaporkan hampir tidak ada penurunan pada usia ini. Umur mempengaruhi terhadap daya tangkap dan pola pikir seseorang. Semakin bertambah umur seseorang akan semakin berkembang pula daya tangkap dan pola pikirnya, sehingga pengetahuan yang diperolehnya semakin membaik dan akan mempengaruhi kinerja seseorang (Notoatmodjo, 2005). Kemampuan berpikir kritis pun meningkat secara teratur selama usia dewasa (Potter \& Perry, 2009).

Pengalaman kerja juga menunjukkan korelasi dengan ketepatan perawat dalam melakukan prosedur triage $(p$-value $=0,000$, tstatistic $=8.039)$. Lama bekerja seseorang akan menentukan banyak pengalaman yang didapatkannya. Sunaryo (2004) mengemukakan bahwa tingkat kematangan dalam berpikir dan berperilaku dipengaruhi oleh pengalaman kehidupan sehari-hari. Hal ini menunjukkan bahwa semakin lama masa kerja akan semakin tinggi tingkat kematangan seseorang dalam berpikir sehingga lebih meningkatkan pengetahuan yang dimiliki. Mirhaghi dan Roudbari (2011) menyatakan bahwa direkomendasikan bahwa setidaknya perawat harus melalui dua tahun pengalaman kerja untuk dapat menjadi perawat gawat darurat yang memiliki kompetensi triage.

Lyneham(1998) jugameneliti proses pengambilan keputusan pada perawat IGD dan menemukan bahwa perawat menggunakan model penalaran klinis dengan memperhatikan informasi verbal, non-verbal dan sumber informasi lainnya dalam menetapkan kategori triage. Perawat yang berpengalaman mendasarkan keputusan mereka pada informasi yang diberikan oleh pasien serta pengalaman masa lalu perawat. Mereka juga mampu menafsirkan isyarat nonverbal untuk membuat keputusan yang paling efisien dan akurat. Sedangkan perawat yang kurang berpengalaman mencari tanda-tanda dan gejala yang ditunjukkan oleh pasien berdasarkan textbook untuk menetapkan keputusan triage. 
Berdasarkan hasil penelitian, didapatkan bahwa ketepatan perawat dalam melakukan prosedur triage pada perawatyang memiliki pengalaman kerja di bawah 3 tahun memiliki rata-rata skor $<80 \%$ bila dibandingkan dengan perawat yang memiliki pengalaman $>5$ tahun. Hal ini sejalan dengan penelitian yang dilakukan oleh Rahmati, et al. (2013) yang menyatakan bahwa skor kinerja personil dengan pengalaman lebih dari tiga tahun lebih tinggi dibandingkan dengan perawat yang memiliki pengalaman kurang dari tiga tahun dan perbedaan antara keduanya adalah signifikan secara statistik. Dan pengalaman bekerja di departemen gawat darurat dikaitkan dengan kesuksesan dalam triage.

Faktor intrinsik perawat lainnya yang juga berhubungan dengan ketepatan perawat dalam melakukan prosedur triage adalah tingkat pendidikan ( $p$-value<0.05). Menurut U.S Departement of labor (2005), lulusan sarjana muda dan diploma atau setingkat merupakan sumber daya yang tumbuh paling signifikan dalam dunia kerja (Potter \& Perry, 2009). Menurut Notoatmodjo (2005), mengatakan bahwa tingkat pendidikan seseorang akan mempengaruhi pengetahuannya. Petugas kesehatan IGD yang dapat melakukan tindakan-tindakan triage minimal berpendidikan DIII (Gurning, 2013).

Berdasarkan hasil penelitian, sebagian besar responden memiliki tingkat pendidikan DIII keperawatan, yaitu sebanyak 26 responden (81,3\%) dan sebanyak 6 responden $(18,7 \%)$ memiliki pendidikan S1 keperawatan. Bila dilihat dari ketepatan dalam melakukan prosedur triage menunjukkan bahwa perawat dengan pendidikan S1 memiliki skor prosentasi di atas rata-rata bila dibandingkan dengan responden yang memiliki tingkat pendidikan DIII. Menurut Grossmann (1999), semakin tinggi tingkat pendidikan, maka semakin mudah mereka menerima serta mengembangkan pengetahuan dan teknologi, sehingga akan meningkatkan produktivitas. Pendidikan akan mempengaruhi proses belajar, makin tinggi pendidikan seseorang maka makin mudah orang tersebut untuk menerima informasi. Semakin banyak informasi yang masuk maka semakin banyak pula pengetahuan yang didapat tentang kesehatan.

Pendidikan juga merupakan salah satu kebutuhan dasar manusia yang diperlukan untuk pengembangan diri. Semakin lama waktu yang digunakan seseorang untuk pendidikan, semakin tinggi kemampuan dan kompetensi melakukan pekerjaan dengan demikian semakin tinggi kinerjanya (Puspitasari., dkk, 2015).

Berdasarkan hasil penelitian memperlihatkan bahwa mayoritas responden telah mengikuti pelatihan BLS (87,5\%) dan PPGD (78\%). Pelatihan yang didapatkan seseorang akan menambah pengetahuan dan skill seseorang dalam membantu pasien yang sedang dalam keadaan gawat darurat. Hal ini sejalan dengan yang dikemukakan oleh Joeharno (2008) bahwa pelatihan yang diselenggarakan kepada petugas kesehatan IGD memberi pengaruh terhadap peningkatan pengetahuan dalam memberikan pelayanan kepada pasien di rumah sakit. Perawat IGD yang dapat melakukan tindakan triage minimal pernah mengikuti pelatihan kegawatdaruratan.

Pengalaman pelatihan memiliki hubungan positif dengan keterampilan dalam triage yang mencerminkan bahwa semakin banyak pelatihan yang diikuti maka, ketrampilan perawat juga akan semakin berkembang. Hal tersebut sejalan dengan studi oleh Forsgren, Forsman, dan Carlstrom (2009) yang menyarankan bahwa pelatihan regular tentang triage dapat meningkatkan keterampilan perawat untuk menangani situasi stres kerja. Mempekerjakan perawat gawat darurat yang berpengalaman dan terampil di triage, serta dengan memberikan pelatihan kepada perawat mengenai bagaimana melakukan triage dengan benar juga dapat mencegah banyak kematian, kecacatan, dan tambahan biaya pengobatan.

Menurut studi Kelly., et al. dalam Rahmati (2013) perawat gawat darurat harus mendapatkan pelatihan tentang triage, dan diyakini bahwa perawat IGD yang baik harus mahir dalam melakukan triage. Berdasarkan hasil penelitian pelatihan memiliki hubungan yang signifikan dengan ketepatan perawat dalam melakukan prosedur triage ( $p$-value $<0.05)$. Selain itu, berdasarkan hasil uji statistik didapatkan bahwa pelatihan memiliki outer loading paling besar $(0,896)$. Hal ini menunjukkan bahwa pelatihan memiliki kontribusi yang paling besar dalam membentuk variabel faktor intrinsik perawat dan paling mendukung perawat dalam ketepatan melakukan prosedur triage. Hasil yang ditunjukkan sejalan dengan penelitian yang dilakukan di kota Lahore, Pakistan, bahwa menurut sebagian besar responden dalam penelitian tersebut merasakan dirinya tidak cukup siap untuk triage, dan 
78\% responden sangat setuju untuk diikutkan dalam pelatihan triage. Perawat perlu memiliki kompetensi dan diikutsertakan dalam pelatihan triage untuk dapat menjalankan pelayanan gawat darurat secara efektif.

\section{KESIMPULAN}

Terdapat hubungan antara tingkat pengetahuanperawat mengenai pelaksanaan triage, keterampilan perawat dalam pelaksanaan triage, sikap dan faktor intrinsik perawat terhadap ketepatan perawat dalam melakukan prosedur triage di IGD. Variabel faktor intrinsik memiliki pengaruh tak langsung terhadap ketepatan perawat dalam melakukan prosedur triage melalui variabel kompetensi perawat sebagai mediasi.

\section{DAFTAR PUSTAKA}

Ajani K. (2012). Triage; a literature review of key concepts. Journal of the Pakistan Medical Association, 62(5):487-489.

Ali S., Taverner B.C.B., Ghani M, et al. (2013). Knowledge of triage among nurses in emergency units. Biomedica, 29:240-243.

Andersson A.K., Omberg M., \& Svedlund M. (2006). Triage in the emergency departmenta qualitative study of the factors which nurses consider when making decisions. British Association of Critical Care Nurse, 11:136-145.

Chen SS., Che, JC., Ng CJ, et al. (2010). Factors that influence the accuracy of triage nurses' judgement in emergency departments. abstract. Emerg Med J, 27(6):451-5. DOI: 10.1136/ emj.2008.059311.

Chung J.Y.M. (2005). An exploration of accident and emergency nurse experiences of triage decision making in Hong Kong. Accident and Emergency Nursing, 13:206-213.

Cone K. and Murray R. (2002). Characteristics, insights, decision making, and preparation of ED triage nurses. Journal of Emergency Nursing, 28(5):401-406.

Cossette S., Cara C., Ricard N., \& Pepin J. (2005). Assessing nurse-patient interactions from a caring perspective: Report of the development and preliminary psychometric testing of
Pelatihan dalam triage adalah amunisi penting bagi perawat untuk menyelesaikan masalah yang dialami pasien dalam kondisi kegawatdaruratan (Ali., et al, 2013).

Berdasarkan hasil tersebut maka untuk meningkatkan kompetensi perawat dalam pelaksanaan triage dapat dilakukan dengan pemberian pelatihan secara berkesinambungan terutama berkaitan dengan pelatihan triage dan kegawatdaruratan lanjutan. Penelitian selanjutnya dapat dikembangkan ke faktor lainnya yang diduga berhubungan dengan ketepatan perawat dalam melakukan prosedur triage seperti faktor pasien (tingkat keakutan pasien), kepadatan lingkungan kerja, beban kerja perawat, motivasi dan etos kerja perawat.

the Caring Nurse-Patient Interactions Scale. International Journal of Nursing Studies, 42:673686.

Emergency Nurses Association. (2011). Position statement: triage qualifications

Fathoni M., Sangchan H., \& Songwatthana P. (2010). Triage skill and related factors among emergency nurses in east java province, Indonesia. The $2^{\text {nd }}$ International Conference on Humanities and Social Sciences.

FitzGerald G., Jelinek G.A., Scot D, et al. (2009). Emergency department triage revisited. Emerg Med J. DOI:10.1136/emj.2009.077081.

Forsgren S., Forsman B., \& Carlstrom E.D. (2009). Working with Manchester triage - Job satisfaction in nursing. International Emergency Nursing, 17: 226-232.

Fry. (2004). Triage nursing practice in Australian emergency department 2002-2004. An ethnography. Department of Family and Community, health Nursing, Faculty of nursing, University of Sidney.

Gerdtz M.F. (2003). Triage nurses' clinical decision making: A multi-methodstudy of practice, processes and influences. School of nursing, Faculty ofMedicine, Dentistry and Health Services, University of Melbourne, Melbourne.

Gerdtz., Chu M., Collins M, et al. (2009). Factors influencing consistency of triage using the 
Australasian Triage Scale: Implications for guideline development. Journal compilation Australasian College for Emergency Medicine and Australasian Society for Emergency Medicine, 21: 277-285. DOI: 10.1111/j.17426723.2009.01197.x.

Göransson K. (2006). Registered nurse-led emergency department triage: organisation, allocation of acuity ratings and triage decision making. Blackwell Publishing Ltd and Elsevier.

Gurning Y., Karim K., Misrawati. (2013). Hubungan tingkat pengetahuan dan sikap petugas kesehatan IGD terhadap tindakan triage berdasarkan prioritas. http//www.jom.unri. ac.id/index.php/JOMPSIK. Diakses pada tanggal 6 September 2016.

Harding A.D., Walker-Cillo G.E., Duke Aet al. (2013). A framework for creating and evaluating competencies for emergency nurses. J Emerg Nurs, 39:252-64.DOI:10.1016/j.jen. 2012. 05. 006

Lusiana L. (2011). Faktor-faktor yang mempengaruhi perawat dalam pelaksanaan triage di UGD RS Puri Indah Jakarta. http://www.digilib. esaunggul.ac.id/public/UEUUndergraduate1647-ABSTRAK.pdf. Diakses tanggal 5 September 2016.

Lyneham J. (1998). The process of decision-making by emergency nurses. Australian Journal of Advanced Nursing, 16(2): 7-14.

Ma'wah M. (2015). Faktor-faktor yang berhubungan dengan kinerja perawat di ruang rawat inap Rumah Sakit Umum (RSU) kota Tangerang Selatan. Skripsi. Fakultas Kedokteran dan Ilmu Kesehatan Universitas Islam Negeri Syarif Hidayatullah. Jakarta.

Mirhaghi \& Roubari. (2011). A survey on knowledge level of the nurses about hospital triage. Iranian Journal of Critical Care Nursing Winter, $4(3): 167-174$.

National Emergency Nurses Affiliation. (2009). Position statement: role of the triage registered nurse. National Emergency Nurses Affiliation Inc.

Nonutu PT., Mulyadi., Malara R. (2015). Hubungan jumlah kunjungan pasien dengan ketepatan pelaksanaan triase di instalasi gawat darurat
RSUP Prof. dr. R.D. Kandou Manado. ejournal Keperawatan (e-Kp), 3 (2).

Notoatmodjo S. (2002). Metode penelitian kesehatan. Jakarta: Rineka Cipta.

Notoatmodjo S. (2005). Metodologi penelitian kesehatan. Jakarta: Rineka Cipta.

Notoatmodjo S. (2007). Promosi Kesehatan dan Ilmu Perilaku. Jakarta: Rineka Cipta.

Puspitasari D.I., Widjajanto E., Rini, IS. (2015). Hubungan kompetensi perawat gawat darurat dengan kinerja perawat di instalasi gawat darurat (IGD) RSUD dr. H. Mohammad Anwar Sumenep dan RSUD Sampang. Jurnal Kesehatan Wiraraja Medika, Hal. 79-88.

Potter \& Perry. (2009). Buku ajar fundamental keperawatan: konsep, proses, dan praktik. Jakarta: EGC.

Rahmati H., Azmoon M., Meibodi M.K, et al. (2013). Effects of triage education on knowledge, practice and qualitative index of emergency room staff: a quasi-interventional study. Bull Emerg Trauma;1(2):69-75.

Sammons S.S. (2012). Accuracy of emergency department nurse triage level designation and delay in care of patients with symptoms suggestive of acute myocardial infarction. Nursing Dissertations. Paper 27. School of Nursing. Georgia State University.

Simamora, R.H. (2012). Buku Ajar Manajemen Keperawatan. Jakarta: EGC.

Simanjuntak (2005). Manajemen dan Evaluasi Kinerja. Lembaga Penerbit Fakultas Ekonomi Universitas Indonesia.

Sunaryo, (2004). Psikologi untuk keperawatan. Jakarta: EGC.

Sunaryo. (2010). Gambaran pelaksanaan triage oleh perawat di instalasi gawat darurat Rumah Sakit Immanuel Bandung. Bandung: STIKES Immanuel Bandung. http://www.rsimmanuel. com. Diakses tanggal 6 September 2016.

Yuliastuti L. (2007). Pengaruh pengetahuan, keterampilan dan sikap terhadap kinerja perawat dalam penatalaksanaan kasus flu burung di RSUP H. Adam Malik. Tesis. Sekolah Pascasarjana Universitas Sumatera Utara. 